\title{
Preparation of "Open/closed" pores of PLGA-microsphere for controlled release of protein drug
}

\author{
M.Odonchimeg ${ }^{1 *}$, S.C.Kim², Y.K.Shim², W.K.Lee ${ }^{2}$ \\ ${ }^{1}$ Institute of Chemistry and Chemical Technology, Mongolian Academy of Sciences, MAS $4^{\text {th }}$ building, \\ Peace Avenue, Bayanzurkh district, Ulaanbaatar 13330, Mongolia \\ ${ }^{2}$ School of Nano Engineering, Inje University, Gimhae 621-749, Korea \\ *Corresponding author: odonchimeg0326@yahoo.com
}

Received: 25 October 2017; revised: 03 January 2018; accepted: 04 January 2018

\begin{abstract}
Poly(D,L-lactic-co-glycolic acid) has been extensively used as a controlled release carrier for drug delivery due to its good biocompatibility, biodegradability, and mechanical strength. In this study, porous PLGA microspheres were fabricated by an emulsion-solvent evaporation technique using poly ethylene glycol (PEG) as an extractable porogen and loaded with protein (lysozyme) by suspending them in protein solution. For controlled release of protein, porous microspheres containing lysozyme were treated with water-miscible solvents in aqueous phase for production of pore-closed microspheres. The surface morphology of microspheres were investigated using scanning electron microscopy (SEM) for confirmation of its porous microstructure structure. Protein property after release was observed by enzymatic activity assay. The pore-closing process resulted in nonporous microspheres which exhibited sustained release patterns over an extended period.
\end{abstract}

Keywords: porous microspheres, lysozyme, PLGA

\section{INTRODUCTION}

Biodegradable polymeric microspheres as an injectable depots for proteins or peptides have been extensively investigated for the past decades [1-7]. Poly(D,Llactideco-glycolide) (PLGA), a biocompatible and biodegradable copolymer, has been mostly used for delivering protein drugs in a sustained manner [1-3]. Various protein drugs were microencapsulated within PLGA microspheres using different formulation methods [4-7]. The most commonly used methods for protein drug encapsulation in polymeric microparticles include solvent extraction or evaporation from a water/oil/water $\left(\mathrm{W}_{1} / \mathrm{O} / \mathrm{W}_{2}\right)$ - dispersion, coacervation, and spray drying. Microencapsulation techniques, however, involve several steps that are detrimental to protein stability, such as exposure of proteins to aqueous/ organic interface, shear induced stress during emulsification, and freeze drying. Under such circumstances, physical destabilization resulting in formation of protein aggregates has been observed. A routine observation made with protein loaded microspheres showing incomplete release of the protein may very well be due to the insoluble aggregates generated during the encapsulation process. In the case with bioactive proteins, significant loss of activity has also been reported. During the release, surface adsorption of protein on microspheres and/or an acidic microclimate generated due to polymer degradation may also cause protein instability. One strategy to overcome these processing problems is to load the drug into preformed porous microspheres. Recently, a new formulation, porous microspheres showing the large porous surface and interconnecting pores interior, has drawn attention for protein delivery [5-10]. Protein could be entrapped into pores of porous microspheres by a solution immersing method. Advantages of this method include that it is a single step not requiring extended shearing/ stirring rates, sonification, or high temperatures. The method is characterized by the absence of an aqueous/ organic interface which is detrimental to protein structure and function [11-15]. In this study, instead of neutralizing the acidic microclimate, a strategy to avoid acid buildup was devised. Aqueous/organic interface was avoided and protein biological activity could be protected during loading process. The porous PLGA microspheres were fabricated by an emulsion solvent evaporation technique using PEG as an extractable porogen and loaded with protein by suspending them protein solution, and their pores were closed by treating with water-miscible solvents.

\section{EXPERIMENTAL}

Materials: $\quad$ Poly(D,L-lactide-co-glycolide) (PLGA) with a lactide/glycolide (L/G) ratio of 50:50 (Mw 48 $\mathrm{kDa}$, inherent viscosity $0.67 \mathrm{dl} / \mathrm{g}$ ) were purchased from Boehringer ingelheim Germany. Hen egg white lysozyme, Micrococcus lysodeikticus, Polyvinyl alcohol

(C) The Author(s). 2017 Open access This article is distributed under the terms of the Creative Commons Attribution 4.0 International License (http://creativecommons.org/licenses/by/4.0/), which permits unrestricted use, distribution, and reproduction in any medium, provided you give appropriate credit to the original author(s) and the source, provide a link to the Creative Commons license, and indicate if changes were made. 
(PVA) $(87-89 \%$ hydrolysed, Mw of $23000-75000 \mathrm{Da})$ and Bicinchoninic acid (BCA) protein assay kit were purchased from Sigma-Aldrich. Poly(ethylene glycol) (PEG) (Mw 10000) was purchased from Aldrich. Unless specified, all other chemicals were of analytical grade and purchased from Aldrich.

Preparation of porous PLGA microspheres: The porous microspheres were prepared by a single oilin-water emulsion method with PEG as pore formers. Briefly, a polymer mixture of PEG and PLGA with varying weight ratios was dissolved in methylene chloride (MC). The polymer solution was emulsified in $100 \mathrm{ml}$ of deionized water containing $0.5 \%$ (w/v) (PVA) for $90 \mathrm{~s}$ at $10000 \mathrm{rpm}$ using a homogenizer. The resultant emulsion solution was placed in a hood under a magnetic stirring condition for $6 \mathrm{~h}$, allowing the solvent to evaporate. The hardened microspheres were centrifuged for $10 \mathrm{~min}$ at $10000 \mathrm{rpm}$, washed three times with deionized water and then freeze-dried.

Encapsulation of protein within porous PLGA microspheres: The porous PLGA microspheres were loaded with lysozyme by suspending them in into $1 \mathrm{ml}$ of lysozyme solution (in $10 \mathrm{mM}$ phosphate buffer, pH 7.4) and gently shaking for $6 \mathrm{~h}$ at $4^{\circ} \mathrm{C}$. The lysozymeloaded microspheres were separated by centrifugation and freeze- dried.

Pore-closing of lysozyme loaded porous microspheres in aqueous condition: Blank porous PLGA microspheres were dispersed in deionized water by vortexing. Water was then added into the suspension as a water miscible solvent while mixing. The final concentration of water miscible solvents in $2 \mathrm{ml}$ of solution was varied from $0 \%$ to $30 \%(\mathrm{v} / \mathrm{v})$. The pore-closing process was terminated by addition of excess water and further incubation for $1 \mathrm{~h}$. The resultant microspheres were centrifuged, washed with deionized water and freeze-dried. In the case of lysozyme incorporated porous microspheres, acetonitrile, Dimethylformamide (DMF) were used as the water miscible solvent, in place of ethanol.

Morphology ofPLGAmicrospheres: The microspheres were coated with platinium by using model Sputter Coater (E-1030, 0-35mA DC, Pt-Pd 8:2, HITACHI, Japan). Surface morphology and internal structure of porous and pore closed microspheres were examined by scanning electron microscopy (FE-SEM, S-4300 SE, HITACHI, Japan). The average sizes of the microspheres and their pores were determined by measuring the diameters of at least 40 of each microsphere and the pore within them.

Total protein content determination: The encapsulation efficiency of lysozyme was determined using the dimethyl sulfoxide (DMSO)/sodium hydroxide $(\mathrm{NaOH}) /$ sodium dodecyl sulfate (SDS) method that described in the literature [15] with a slight modification. The microcapsules, after solidification and washing in distilled water, were freeze-dried and stored at $4^{\circ} \mathrm{C}$, prior to the measurement. Microcapsules $(10 \mathrm{mg})$ were placed into a test tube to which DMSO $(0.2 \mathrm{ml})$ was added to dissolve the polymer portion of the microcapsules. Then, $0.8 \mathrm{ml}$ of $0.05 \mathrm{~N} \mathrm{NaOH}$ solution containing $0.5 \%$ SDS was added to allow solubilization of the protein and hydrolysis of PLGA. The resulting mixture was sonicated for $90 \mathrm{~min}$ at $25^{\circ} \mathrm{C}$ and centrifuged at $10000 \mathrm{rpm}$ for $10 \mathrm{~min}$. The clear supernatant $(25 \mu \mathrm{l})$ was transferred into a 96 -well microplate. The protein concentration was determined with Bicinchoninic acid assay (BCA protein assay reagent kit), by colorimetric analysis at $562 \mathrm{~nm}$ with a fluorescence multi-Detection reader (Synergy HT, USA). The encapsulation efficiency $(E)$ was defined as follows:

$$
E=\frac{\text { amount of encapsulated protein }}{\text { total amount of feed protein }} \times 100
$$

In vitro release study: In vitro protein release from microspheres was evaluated by an in vitro dissolution test. Amounts of $20 \mathrm{mg}$ of microspheres were dispersed in $4 \mathrm{ml}$ PBS $\left(\mathrm{pH} \mathrm{7.4)}\right.$ containing $0.01 \% \mathrm{NaN}_{3}$, the suspensions were kept at $37^{\circ} \mathrm{C}$ and shaken moderately. At predetermined time intervals, $1 \mathrm{ml}$ of medium, from each sample, were removed and replaced with fresh PBS buffer. The amount of protein released was determined at $562 \mathrm{~nm}$ by Bicinchoninic acid assay (BCA).

Degradation study of PLGA microspheres: Preweighed PLGA microspheres (about $10 \mathrm{mg}$ ) were placed in individual test tubes containing $4 \mathrm{ml}$ of phosphate buffered saline (PBS, $0.1 \mathrm{M}, \mathrm{pH}$ 7.4). The tubes were kept in an incubator that was maintained at $37^{\circ} \mathrm{C}$. At predetermined degradation intervals, the microspheres were collected by centrifugation, washed with distilled water to remove residual buffer salts, and dried to constant weight in vacuum desiccators. The degradation medium was collected to characterize the $\mathrm{pH}$ change during the degradation process. The surface morphology of degraded PLGA microspheres was analyzed using SEM at $12 \mathrm{kV}$.

\section{RESULTS AND DISCUSSION}

PEG was selected as the water extractable porogen to make the porous PLGA microspheres [17]. Figure 1 shows the morphological change of PLGA microspheres from a non-porous to an open cellular porous structure with increasing weight ratio of PEG/PLGA. Morphologically, SEM revealed that control microspheres showed a smooth, nonporous surface while the microspheres with PEG exhibited a highly porous surface.

The porosity of microspheres increased with an increasing amount of PEG. The reason for selecting PEG is that it is an uncharged, linear and hydrophilic and easily extractable in aqueous phase. For preparing the porous microspheres, a blend mixture of PEG and PLGA was co-dissolved in a disperse phase of methylene chloride (MC), and the volatile solvent was slowly removed from the embryonic MC droplets within the aqueous continuous phase. As the embryonic MC droplets containing PEG and PLGA were in contact with aqueous phase, the influx of water and concomitant out flux of $M C$ caused a phase separation, giving rise to a PLGA-rich phase and a PEG-rich phase [18]. During solvent removal, water-soluble PEG was also leached out into the outer aqueous phase, therefore sufficient MC removal produced a porous skeletal structure of 

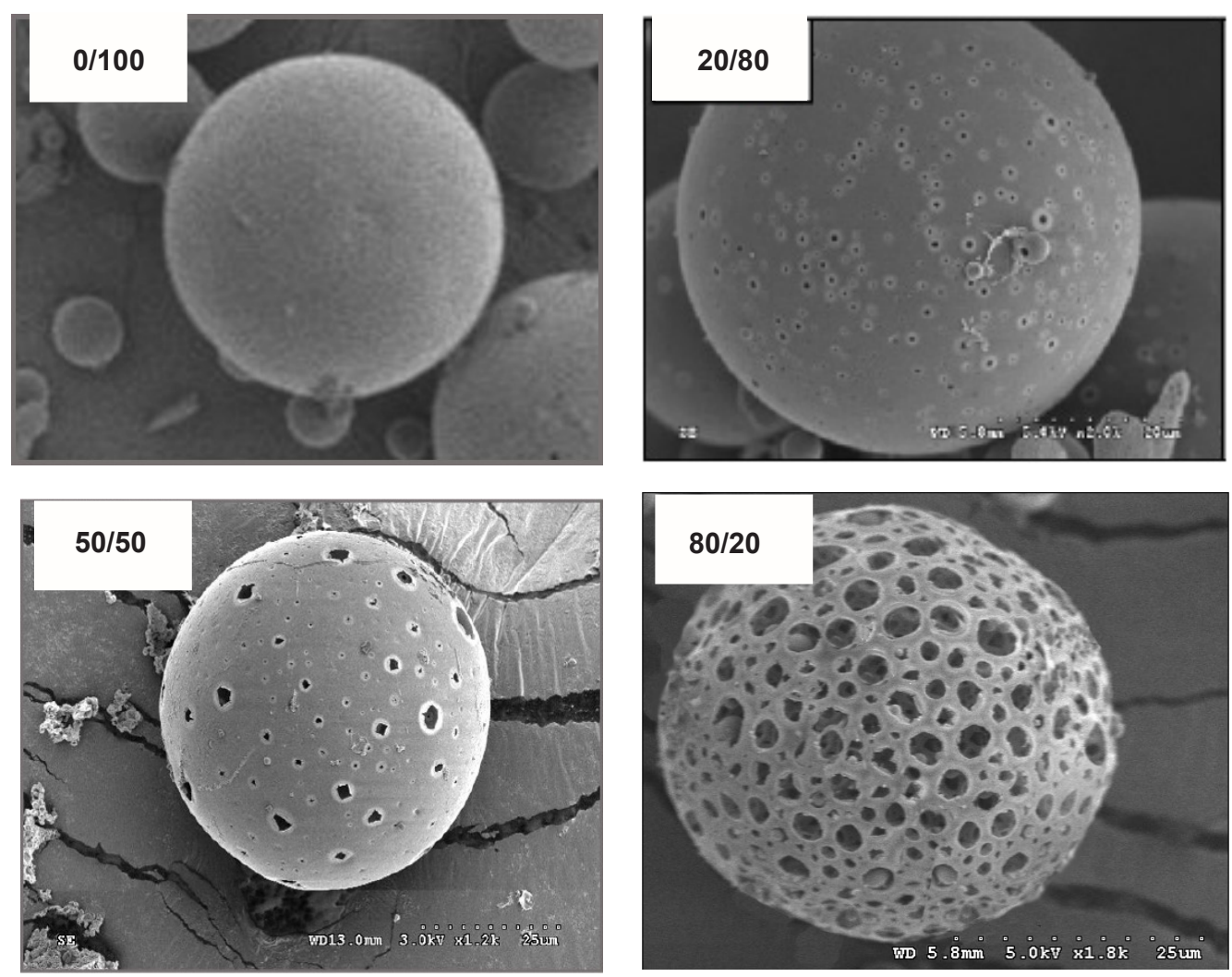

Fig. 1. SEM images of PLGA microspheres prepared with increasing the weight ratio of PEG/PLGA.

channels. This swollen polymer structure is expected to increase exchange of polymer degradation products with the surrounding medium, minimizing the risk of acid induced protein degradation [19]

It can be seen in Figure 2 that the average diameter of porous microspheres increased from $9.38 \mu \mathrm{m}$ - to 38.9 $\mu \mathrm{m}$ while that of the size of surface pores increases from 0-2.64 $\mu \mathrm{m}$ with increasing weight ratio of PEG/PLGA. This results from increasing the fractional volume of the hydrophilic PEG phase within the blend mixture, which in turn imbibes more water into the droplets, enlarging the size of embryonic MC droplets. The hardening of these

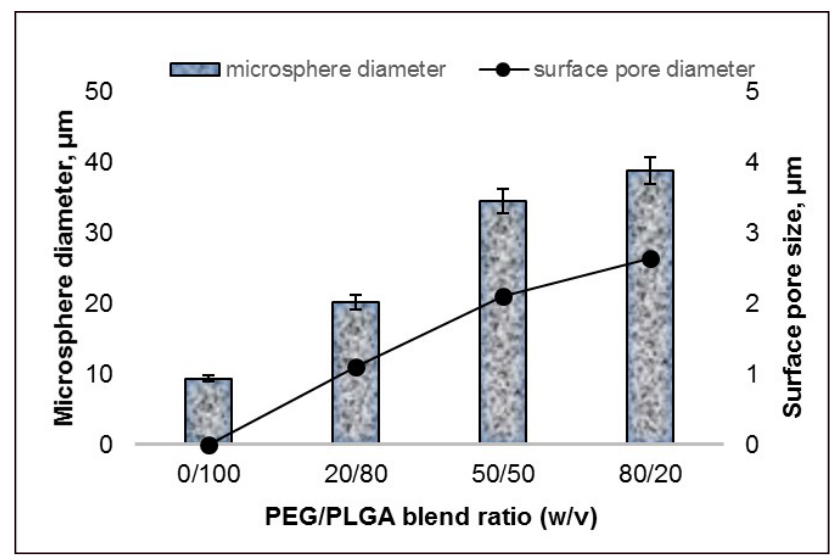

Fig. 2. The average diameter of microspheres and surface pores as function of PEG/PLGA weight ratio.

Each bar is the mean of \pm standard deviation of at least three experiments. The error bars indicate the standard deviation between the averages. droplets produced larger microspheres. PVA concentration in the external water phase is known to be a factor that influences the size of microspheres. In the present study, the porous microspheres were prepared by varying the concentration of PVA solution. Fixing the weight ratio of PEG/PLGA at 20/80, the concentration of PVA solution varied from $0.5 \%$ to $4 \%$. As the concentration of PVA solution increasing, the mean size decreased from $38.9 \mu \mathrm{m}$ to $22.6 \mu \mathrm{m}$. The effect of PVA concentration the volume mean diameter is shown in Table 1. The decrease in particle size of microspheres was occurred because that the viscosity of PVA solution

Table 1. Variation in PEG/PLGA microspheres size as a function of PVA concentration in the emulsion water phase.

\begin{tabular}{cccc}
\hline \multirow{2}{*}{$\begin{array}{c}\text { PVA in water } \\
\text { phase (\%, w/v) }\end{array}$} & \multicolumn{3}{c}{ Particle size, $\mu \mathrm{m}$} \\
\cline { 2 - 4 } & $\mathbf{d}(\mathbf{0 . 1})$ & $\mathbf{d}(\mathbf{0 . 5})$ & $\mathbf{d}(\mathbf{0 . 9})$ \\
\hline 0.5 & 16.06 & 38.9 & 70.2 \\
1.0 & 8.24 & 31.8 & 67.2 \\
2.0 & 4.55 & 27.8 & 76.7 \\
3.0 & 7.69 & 30.7 & 70.3 \\
4.0 & 4.03 & 23.6 & 68.28 \\
\hline
\end{tabular}

increased as the concentration increased, which affects the dispersibility of emulsion droplets in the continuous phase and efflux velocity of PEG phase. The stirring speed of the dispersive process was a key factor to affect the morphology of porous microspheres. It was found that the high stirring speed would destroy the spherical 
structure of porous microspheres and formed spongelike structures with irregular shape. It was because that porous structure had degraded the mechanical property of the microspheres system. The spherical structure of microspheres would be destroyed during stirring, which could provide the shearing force to destroy the system (Figure 3).
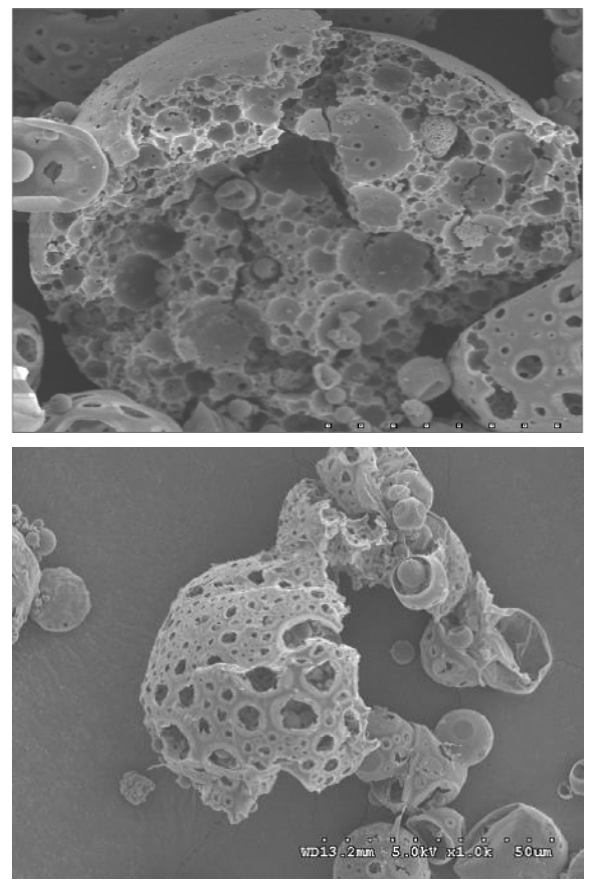

Fig. 3. Destroyed porous microspheres during stirring process.

In conclusion, porous microspheres with a highly interconnecting pores and large porous surface were prepared with this condition in further study. The process conditions optimized at 80/20 PEG/PLGA weight ratio, PVA solution concentration $0.5 \%$ and $3 \% \mathrm{MC} /$ water volume ratio gave production of the porous PLGA microspheres with interconnected pores. Using these porous PLGA microspheres, we intended to achieve sustained release of protein drugs. In many cases, proteins have been encapsulated with in biodegradable microspheres by a double emulsion W/O/W technique because of their limited solubility in organic solvents. Although the use of organic solvents in the formulation process deactivates biological activity of the encapsulated protein to a great extent, they are unavoidably required to prepare the protein encapsulated PLGA microspheres [20]. Klibanov and co-workers have shown that the conformation of solid proteins in organic solvents is kinetically trapped [21]. Thus, protein unfolding is extremely slow under these preparation conditions. Problems may arise, however, when the protein (partially) dissolves in the organic phase. The latter often results in unfolding [22, 23]. In this study, lysozyme was loaded into porous microspheres by a simple solution immersing method without any harsh preparation conditions, such as the aqueous/organic interface produced by a water-in-oil microemulsion and the acute shearing strength brought by a high-speed homogenizer or a sonicater. Thus, protein denaturation and aggregation happened on aqueous/organic interface can be avoided in loading process. Protein loading on biomaterials is a complicated physiochemical process and has widely researched. In this study, the effect of loading temperature and incubation time on lysozyme into porous microspheres were examined. Protein loading was carried out at $4^{\circ} \mathrm{C}$ in this study, which was a mild environment for protein activity. The protein loading increased with increasing incubation time.

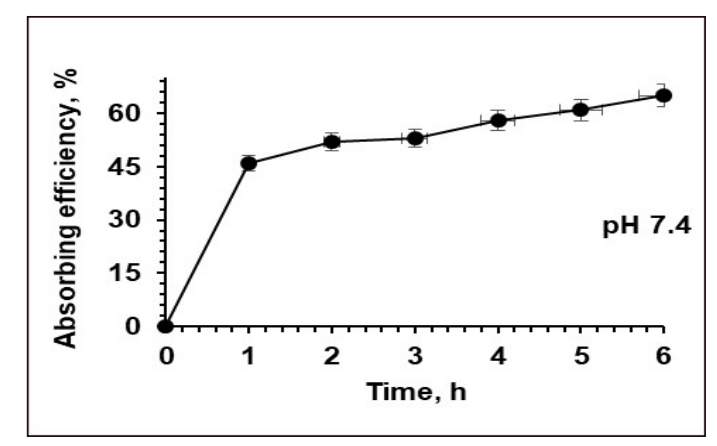

Fig. 4. Time dependent loading efficiency.

Shown in Figure 4, the adsorption amount of lysozyme almost reached the zenith and kept stable value after 6 hours. Then the suspension was treated with water-miscible solvents in aqueous solution to close the pores. Attempts for closing the pores were tried by using water-miscible solvents that partially dissolved PLGA. Figure 5 shows pore-closed of blank porous PLGA microspheres treated with an aqueous solutions
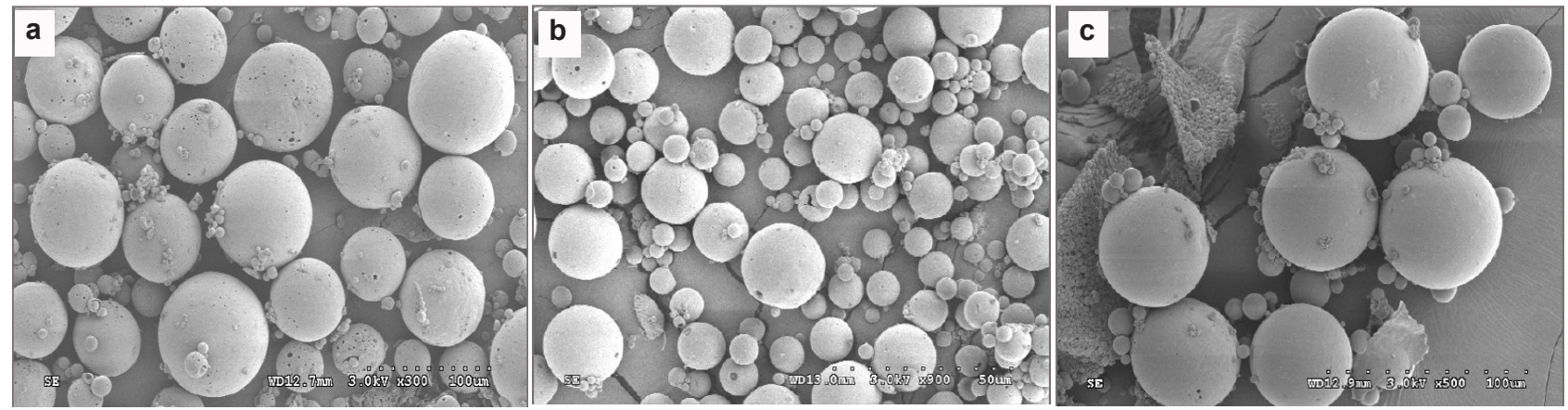

Fig. 5. SEM images of open/closed PLGA microspheres PEG/PLGA porous microspheres at ratio of 80:20 were treated with different aqueous solutions at suitable concentration (v/v). a. DMSO 20\%, b. DMF 20\%, c. EtOH 30\%. 
containing different concentrations. It can be seen that the surfaces pores are gradually closed with increasing the water miscible solvent/water volume ratio. Moreover, the pore closed microspheres did not aggregate and were able to maintain its spherical shape. Particularly, ethanol does not completely dissolve the raw PLGA particles to a clear solution state, but makes them swell into rubbery and sticky state. An ethanol volume fraction at $30 \%$ produced nonporous microspheres. The increased volume fraction of ethanol in aqueous phase caused to partially dissolve PLGA skeletal structure of porous microspheres to collapse, and unlimitedly closed the pores by fusion of the surrounding PLGA polymer phase. When the ethanol/water volume ratio was over $30 \%$, most of the microspheres were aggregated and precipitated due to collision-induced fusion of partially dissolved porous microspheres (Figure 6).

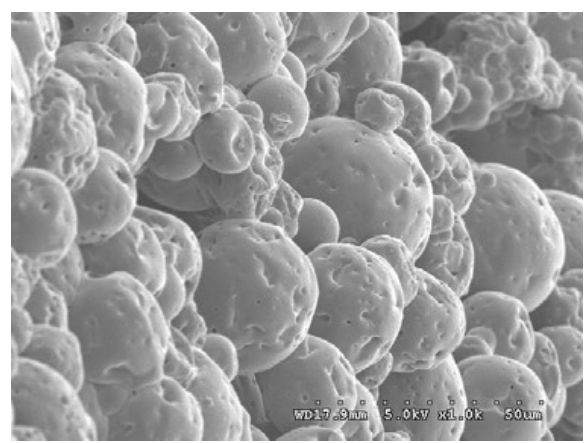

Fig. 6. Partially dissolved porous microspheres

Protein release from polymeric microspheres was depending on degradation of polymers and the protein diffusion out from microspheres [23].

Generally, these two ways happened at same time in release process. Therefore, the release curve was made up of two phases, the burst release followed by a stable release stage. In the burst release phase, the protein adsorbed on the surface of microspheres diffused out quickly first few hours. Burst release was not beneficial to patients who needed long term treatments. Seen from Figure 7 , it can be found that $88.7 \%$ of lysozyme loading in the porous microspheres was released at first day.

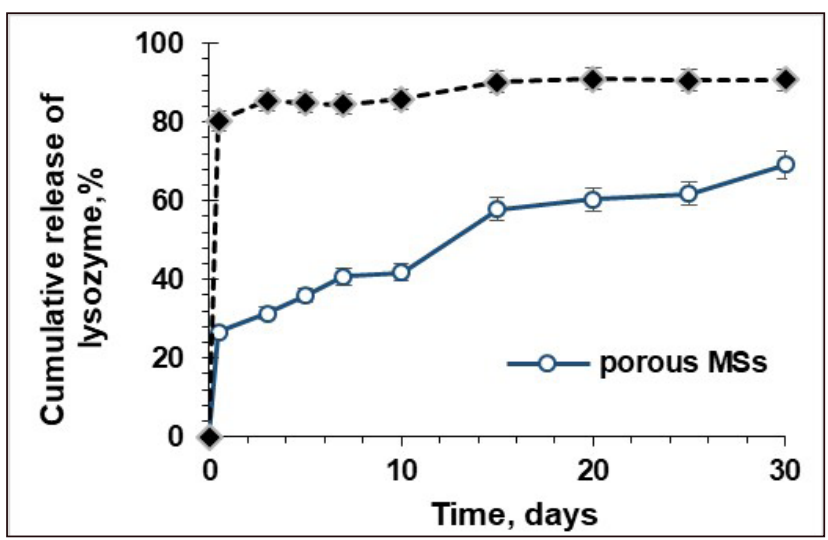

Fig. 7. In vitro release of lysozyme from porous and pore closed microspheres. Each bar is the mean of three experiments \pm standard deviation

In the case of porous microspheres, most of the loaded protein immediately diffused out through water-filled porous and inter connected channels, as expected, the initial burst showed high percent. On the other hand, pore closed microspheres showed much slower release patterns, caused by the creation of a diffusion barrier to the encapsulated protein. The closed surface pores resulted in reduced diffusion rates of encapsulated protein as shown in Figure 7.
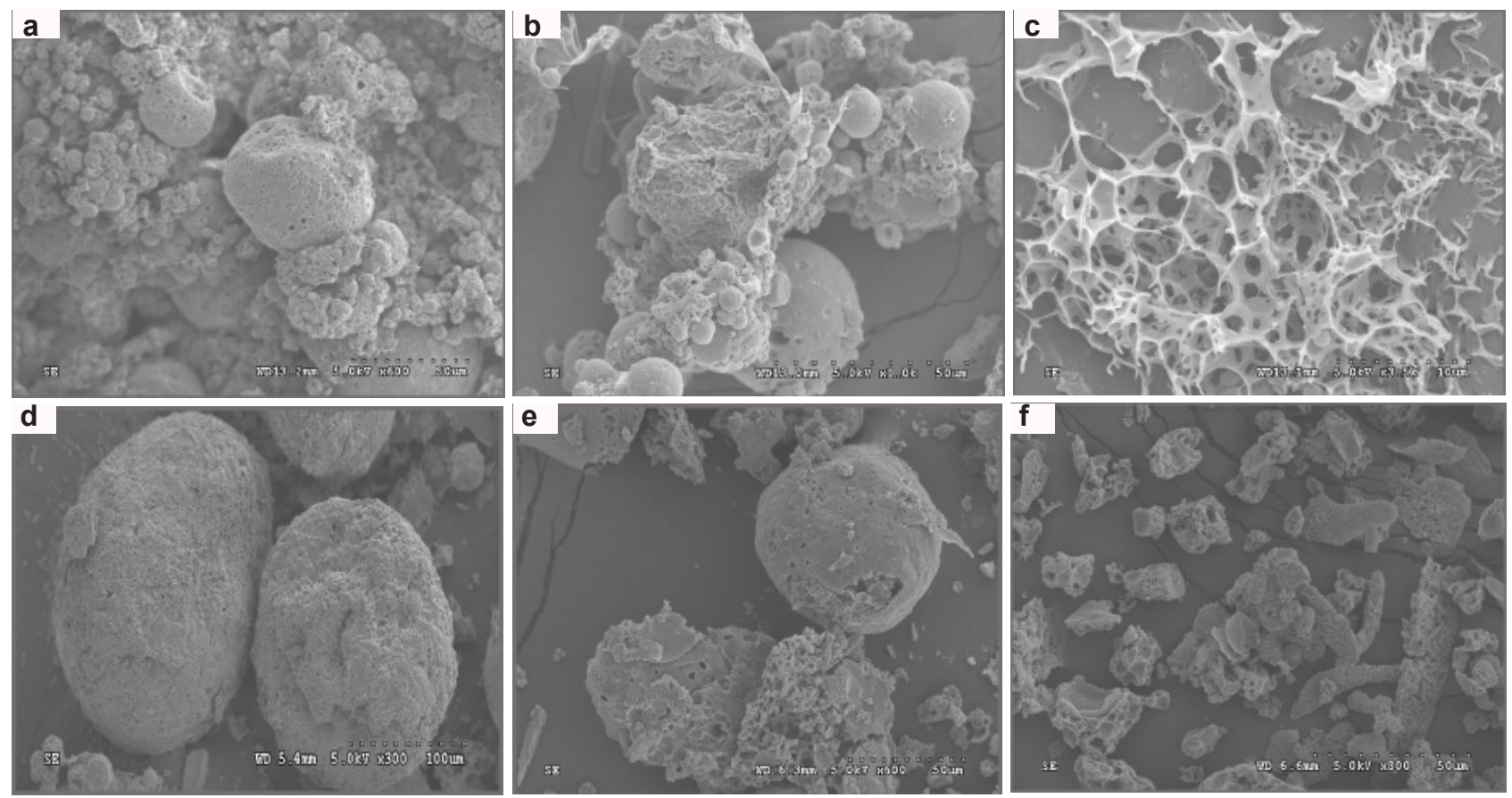

Fig. 8. The morphological changes of microspheres during degradation processing detected by SEM. Porous PLGA microspheres $(a-c)$ and porous microspheres treated by ethanol (d-f) degradated for 1,3 and 5 weeks, respectively. 
The initial burst was also greatly reduced from $85.6 \% \pm$ 2.5 to $26.3 \% \pm 1.1$. In this study, protein was loaded with in porous microspheres by a simple immersing process, thus avoiding the solvent/water interface problem during formulation. However, the pore closed microspheres prepared by treating with the water miscible solvent had a serious shortcoming: insufficient drug loading amount. Although the porous microspheres showed high of initial drug loading amount, nonporous microspheres produced by the solvent treatment showed sharp decrease in drug loading amount. Entrapped hydrophilic molecules within the porous microspheres were quickly dissolved and diffused out to the outer aqueous phase before the pore closing process took place. Microspheres surface charge density was modified successfully using PLGA and Polyelectrolyte polymer blends, and these microspheres were used to investigate the loading capacity of lysozyme, a model electropositive protein. Furthermore, it is noteworthy mention that the protein maintained its structural integrity after this preparation. In order to investigate the degradation of microspheres, the change in surface morphology of the pore closed microspheres with time after incubation with PBS, porous microspheres as a control. The morphological change of porous microspheres and pore closed microspheres during degradation process was shown in Figure 8.

The surface morphology of porous microspheres in degradation of 1, 3 and 5 weeks were shown in Figure 8(a), (b) and (c) respectively. The porous microspheres lost their spherical structure in 1 week degradation. This fast deformation was due to the porous structure, which made water penetrate into the microspheres matrix easily and the hydrolysis was the dominant way in polymer degradation. After 5 weeks the porous microspheres were totally collapsed. While, the pore closed microspheres retained their spherical structures in 1 week degradation, shown in Figure 8(d).

The pore closed microspheres collapsed and lost their spherical structure after 3 weeks degradation as shown in Figure 8(e). In conclusion, the morphological change of porous microspheres was faster than pore closed microspheres.

\section{CONCLUSIONS}

Porous PLGAmicrospheres were prepared by a single-oilwater emulsion method using PEG as water extractable porogen. The weight ratio of PEG/PLGA and MC/water volume ratio were two of the most important factors in determining the size of microspheres, pore diameter and their morphology. The resulting interconnected porous microspheres were readily transformed to nonporous microspheres by treating with water-miscible solvents under aqueous conditions. When protein was loaded within porous microspheres by an aqueous immersing method, careful selection of water-miscible solvents was necessary for effective pore closing process. The resultant nonporous microspheres exhibited sustained release profiles over and extended period, but the drug loading amount was not satisfactory and subject to further study.

\section{REFERENCES}

1. Fu K., Harrel. R., Zinski K. (2003) A potential approach for decreasing the burst effect of protein from PLGA microspheres. J. Pharm. Sciences, 92, 1582 - 1591

2. Langer R. (2003) Biomaterials in drug delivery and tissue engineering: one laboratory's experience. Acc. Chem. Re., 33, 94-101.

3. Gombotz W.R., Pettit D.K. (1995) Biodegradable polymers for protein and peptide drug delivery. Bioconjugate Chem., 6, 332-351.

4. Park T.G, LeeH.Y., Nam Y.S. (1998)Anew preparation method for protein loaded poly (D,L-lactic-coglycolic acid) microspheres and protein release mechanism study. J. Control. Rel., 55, 181-191.

5. Singh M., Shirley B., Bajwa K., Samara E., O'Hagan. (2001) Controlled release of recombinant insulin-like growth factor from a novel formulation of polylactideco-glycolide microparticles. J. Control. Re., 70, 21-28.

6. Kim H.K., Park T.G. (2001) Microencapsulation of dissociable human growth hormone aggregates within PLGA microparticles for sustained release. International Journal of Pharm., 229, 1 07-116.

7. Sun L., Zhou S., Wang W., Li.X., Weng J. (2009) Preparation and characterization of porous biodegradable microspheres used for controlled protein delivery. J. Colloids and Surfaces A., 34, 173-181.

8. Supersaxo A., Kou J.K, Teitelbaum P., Maskiewicz R. (1992) Preformed porous microspheres for controlled and pulsed release of macromolecules. $J$. Control. Release, 23, 157-164.

9. Duggirala S.S., Mehta R.C., DeLuca P.P. (1996) Interaction of recombinant human bone morphogenetic protein-2 with poly(DL-lactide-coglycolide) microspheres. Pharm. Dev. Tech., 1, 11-19.

10. Zegzula H.D., Buck D.C., Brekke J., Woznney J.M., Hollinger J.O. (1997) Bone formation with use of rhBMP-2 (recombinant human bone morphogenetic protein-2). J. Bone Joint Surg., 79, 778-1790.

11. Boyan B.D., Lohmann C.H., Somers A., Niederauer G.G., Wozney J.M., Dean D.D., Carnes D.L., Schwartz Z. (1999) Potential of porous poly$D, L$-lactidecoglycolide particles as a carrier for recombinant human bone morphogenetic protein-2 during osteo induction in vivo. J. Biomed. Mater., 46, 51-59.

12. Puri N., Jones A.B., Kou J.H., Wyandt C.M. (2000) Release of bovine serum albumin from preformed porous microspheres of poly(L-lactic acid). J. Microencapsul., 17, 207-214.

13. Ahmed A.R., Bodmeier R. (2002) Drug adsorption and release from preformed porous biodegradable microparticles. $17^{\text {th }}$ Meeting of the American Association of Pharmaceutical Scientists, AAPS, Toronto, Ontario, Canada, 10-14 November, 55.

14. Jiang B.H., Woo B.H., Kang F., Singh P.P. (2002) Assesement of protein release kinetics, stability and protein polymer interaction of lysozyme encapsulated poly(D,L-lactide-co-glycolide) micro- 
spheres. J. Control. Rel., 79, 1377-145.

15. Kim H.K., Park T.G. (2004) Comparative study on sustained release of human growth hormone from semi-crystalline poly(l-lactic acid) and amorphous poly (D,L- lactic-co-glycolic acid) microspheres: morphological effect on protein release. J. Control. Rel., 98,115-125.

16. Song C.X., Labhasetwar V. (1997) Controlled release of U-86983 from double-layer biodegradable matrices: effect of additives on release mechanism and kinetics. J. Control. Rel., 45,175-192.

17. Van de Witte P., Dijkra P.J. (1997) Meta stable liquid-liquid and solid-liquid phase boundaries in polymer-solvent-nonsolvent systems. J. Polym. Sci. $B$, 35,763-770.

18. Nam Y.S., Park T.G. (1999) Porous biodegradable polymeric scaffold prepared by thermally induced phase separation. J. Biomed. Mater., 47, 8-17.

19. Tae G. P., Hee Y.L., Yoon S.N. (1998) A new preparation method for protein loaded poly(D,L-lacticcoglycolic acid) microspheres and protein release mechanism study. J. Control. Rel., 55,181-191.
20. Griebenow K., Klibanov A.M. (1996) On protein denaturation in aqueous-organic mixtures but not in pure organic solvents. J. Am. Chem. Soc., 118, 11695-11700.

21. Griebenow K., Klibanov A.M. (1997). Can conformational changes be responsible for solvent and excipient effects on the catalytic behavior of subtilisin Carlsberg in organic solvents. Biotechnol. Bioeng. 53, 351-362.

22. Knubovets T., Osterhout J.J., Klibanov A.M. (1999) Structure of lysozyme dissolved in neat organic solvents as assessed by NMR and CD spectroscopies. Biotechnol. Bioeng. 63, 242-248.

23. Giteaua I.A., Venier-Juliennea M.C., AubertPouësselb A., Benoitanter J.P. (2008) How to achieve sustained and complete protein release from PLGA-based microparticles. National Journal of Pharmaceutic, 350, 14-26 